\section{International}

Journal of $\int_{1}$ hysical
DOI : $10.15740 / \mathrm{HAS} / \mathrm{IJPE} / 8.1 / 58-61$

e ISSN-0976-7924 Visit us : www.researchjournal.co.in

\title{
Investigation of selected anthropometric measurements, physical, physiological variables as predictors of fast drag flick in hockey
}

\section{SANI KUMAR VERMA}

Received : 23.12.2014; Accepted : 24.03.2015

Author for correspondence

SANI KUMAR VERMA

Department of Physical Education,

Institute of Professional Studies,

GWALIOR (M.P.) INDIA

\section{-ABSTRACT}

The purpose was to investigate the combine contribution of anthropometric measurements, physical variables and physiological variables to fast drag flick in hockey. Thirty (30) male drag flickers were selected as subjects for the purpose of this study. The selection of subjects was based on their participation in national level tournaments. The subjects belonged to various states and union territories. The standing height, weight, leg length, upper arm length, fore arm length, chest girth, shoulder width, upper arm girth and fore arm girth were the anthropometric measurements; arm and shoulder strength, back strength, leg strength, grip strength and back flexibility were the selected physical variables and positive breath holding capacity, anaerobic capacity, cardiovascular endurance and percentage of fat were the selected physiological variables. The Speed of the hockey ball during drag flick skill was measured by a Speed Radar Gun. To investigate the combined contribution of the anthropometric measurements, physical variables and physiological variables to the fast drag flick in hockey, multiple correlation was computed at 0.05 level of significance. It is also concluded that multiple correlation of anthropometric measurements, physical variable and physiological variables taken together in relation to the fast drag flick resulted in significant correlation.

- KEY WORDS : Anthropometric measurements, Physiological variables, Fast drag flick

- HOW TO CITE THIS PAPER : Verma, Sani Kumar (2015). Investigation of selected anthropometric measurements, physical, physiological variables as predictors of fast drag flick in hockey. Internat. J. Phy. $E d u ., 8(1): 58-61$. 